\title{
Variability of electrocardiographic and enzyme evolution of myocardial infarction in man
}

\author{
SALIM YUSUF, ROBERTO LOPEZ*, ALAN MADDISON, PETER SLEIGHT \\ From the Department of Cardiovascular Medicine, Fohn Radcliffe Hospital, Headington, \\ University of Oxford, Oxford
}

SUMmaRY We have studied the time course of development of ST segment elevation, $R$ wave loss, and $Q$ wave development in 41 patients using 35 lead praecordial mapping or 12 lead electrocardiograms in those with anterior and inferior infarcts, respectively. The first recording was at a mean time of six hours after the onset of pain; subsequent records were taken every eight hours for 24 hours, every 12 hours for the second day, and every day thereafter. Serial CK MB estimates were obtained at every four hours for the first $\mathbf{7 2}$ hours. There was good agreement in the time course between the electrocardiogram and enzyme evolution.

Forty-one per cent of patients showed rapid infarction with $R$ wave and $Q$ wave evolution complete within 12 hours of pain and accompanied by a short duration of enzyme release (mean $=19 \cdot 30$ hours). Fifty-nine per cent of patients showed more prolonged infarction with longer $R$ wave and $Q$ wave evolution and enzyme release (mean $=30$ hours). Four patients also showed delayed reinfarction. ST segment elevation was maximal at six hours in the whole group and was significantly lower thereafter. Patients with rapid infarction showed high initial ST segment elevation which decreased promptly compared with those with prolonged infarction, who showed moderate but more persistent ST segment elevation.

This study shows the variability in the time course of the electrocardiogram and enzyme evolution after myocardial infarction in man.

Studies in experimental animals have suggested that ischaemic injury after coronary occlusion can be altered by different pharmacological, metabolic, or mechanical interventions. ${ }^{1}$ With the exception of two studies ${ }^{2}{ }^{3}$ these reports have been based on the initiation of the test treatment either before or within the first 30 minutes after coronary occlusion. Data obtained from such animal experiments cannot be extrapolated to man since myocardial infarction may be much more complex than ligation, ${ }^{4}$ and the test treatment may be administered late because of the delay between the onset of symptoms and the call for medical aid. ${ }^{5}$

If interventions designed to limit infarct size are to be successful in clinical practice, these measures must be applied before muscle death is complete. In a previous study, we have shown that the maximal loss of $\mathbf{R}$ waves and the development of $Q$ waves are reliable quantitative indices of myo-

*Present address: Centro Medico Docente La Trinidad Aptdo Postal 80474 Caracas, Venezuela.

Received for publication 20 June 1980 cardial necrosis in man. ${ }^{6}$ The aim of this study is to quantify the evolution of these electrocardiographic markers of myocardial necrosis in a group of patients admitted to the coronary care unit. We have also examined the time course of the ST segment evolution in relation to $R$ wave and $Q$ wave changes and related the duration of these changes to the duration of enzyme release.

\section{Patients}

We studied 41 consecutive patients, aged between 46 and 75 years (mean 62.5 years), admitted to the coronary care unit of the Radcliffe Infirmary with evidence of a recent transmural myocardial infarction on a 12 lead electrocardiogram and with a significant increase in cardiac enzymes. Patients with intraventricular conduction defects (QRS duration $>100 \mathrm{~ms}$ ) including hemiblock and second and third degree atrioventricular block were excluded. All patients had normal frontal axes $\left(0^{\circ}\right.$ to $\left.+90^{\circ}\right)$. 
Of the 41 patients, 37 gave no history of a previous infarct, and a previous electrocardiogram was available in 14 of these. Twenty-seven patients had anterior infarcts and 14 had inferior infarcts; none of the four with a history of previous infarction had pathological $Q$ waves on their initial electrocardiogram. Four patients later developed reinfarction as shown by new electrocardiographic and enzyme changes. Routine management of the patient was not altered by the study procedure; diuretics and antiarrhythmic drugs were administered as clinically indicated. Lignocaine was given to eight patients, 11 patients received oral betablockers, and disopyramide was used in only one patient. No patient had a systolic blood pressure less than $90 \mathrm{mmHg}$. Three patients required cardioversion for ventricular fibrillation, none of whom showed a further rise in CK MB.

\section{Methods}

\section{PRAECORDIAL ELECTROCARDIOGRAPHIC} MAPPING

Praecordial electrocardiographic mapping was done in all patients with anterior myocardial infarction. Thirty-five praecordial sites were selected by focusing an ordinary projector beam through a $35 \mathrm{~mm}$ slide with 35 holes arranged in five horizontal rows and seven vertical rows. The horizontal rows were designated from top to bottom $A$ to $E$ and the vertical rows from right to left one to seven. The distance between the first and second vertical rows was twice the distance between the others to avoid electrode placement on the sternum. With the patient sitting up at 45 degrees, A1 was focused on a point $2.5 \mathrm{~cm}$ to the right of the sternal edge in the second intercostal space. E1 was focused $2 \mathrm{~cm}$ below the level of the xiphisternum in the same line as A1. The position of the projector was adjusted so that A7 fell on a spot high in the left mid-axillary line in such a way that rows $A$ to $E$ were horizontally placed. All spots were then marked using indelible ink to allow accurate repositioning of the electrodes each time a recording was obtained.

The electrocardiograms were recorded using a four-channel ink-jet Elema-Schönander Mingograf 34 recorder. Suction cup electrodes with a contact diameter of $15 \mathrm{~mm}$ were used. The electrocardiogram was recorded from each praecordial site at two different gains simultaneously $(1 \mathrm{mV}=10 \mathrm{~mm}$ and $1 \mathrm{mV}=40 \mathrm{~mm}$ ) so that an accuracy of 0.025 $\mathrm{mV}$ could be obtained. Paper speed was $25 \mathrm{~mm} / \mathrm{s}$.

Each recording was made during quiet breathing and great care was taken to reposition the patient at the same angle on each occasion. The first recording was obtained at a mean time of six hours after the onset of pain. Subsequently, recordings were obtained at eight-hourly intervals during the first 24 hours, at 12-hour intervals on the second day, and thereafter daily.

Initial studies showed that praecordial electrocardiographic mapping was of limited value in inferior infarction. Therefore, in order to record changes from the inferior surface of the heart, the standard 12 lead electrocardiogram was recorded serially, the $\mathrm{V}$ lead positions being marked on the chest wall to obtain reproducible recordings.

\section{ELECTROCARDIOGRAPHIC MEASUREMENTS \\ Patients with anterior infarction}

The amplitude of the $Q, R$, and $S$ waves, and of ST segment elevation (at $60 \mathrm{~ms}$ after the $\mathrm{J}$ point) was measured in five beats from each site, using the TP segment as a baseline. Measurements were made on both the magnified $(1 \mathrm{mV}=40 \mathrm{~mm})$ and standard recordings $(1 \mathrm{mV}=10 \mathrm{~mm})$. These were then summed from 35 leads to obtain $\Sigma R$, $\Sigma \mathrm{Q}, \Sigma \mathrm{S}$, and $\Sigma \mathrm{ST}$. In addition, $\Sigma(\mathrm{Q}+\mathrm{S})$ and $\Sigma \mathrm{R} / \Sigma(\mathrm{Q}+\mathrm{S})$ were calculated for each map.

\section{Patients with inferior infarction}

In patients with inferior infarction, QII + III +aVF and ST segment elevation in II + III + aVF were calculated.

\section{SERIAL CK AND CK MB ANALYSES}

Blood samples were obtained from a peripheral vein through an indwelling cannula at four-hourly intervals for 72 hours after the onset of pain. Samples were immediately centrifuged for 15 minutes. Plasma was pipetted into plain sterile glass tubes and stored at $-20^{\circ} \mathrm{C}$. CK was estimated using the method of Oliver ${ }^{7}$ with dithiothreital as activator as utilised by the Searle CPK-UV ${ }_{11}$ kit. The method described by Mercer and Varat $^{8}$ was used to separate the $\mathrm{CK}$ isoenzymes.

CK MB AND MATHEMATICAL

CALCULATIONS

The appearance function of $\mathrm{CK} M B$ released from the infarcted myocardium was calculated (cumulative CK MB) by the method described by Sobel et al. ${ }^{9}$ and modified by Norris et al. ${ }^{10}$ Enzyme release was assumed to be completed when the appearance curve reached a plateau.

\section{REPRODUCIBILITY STUDIES IN} CONTROL SUBJECTS

Three groups of control subjects were studied: (i) A group of patients aged between 45 and 75 years admitted to the ophthalmic and ENT wards, 


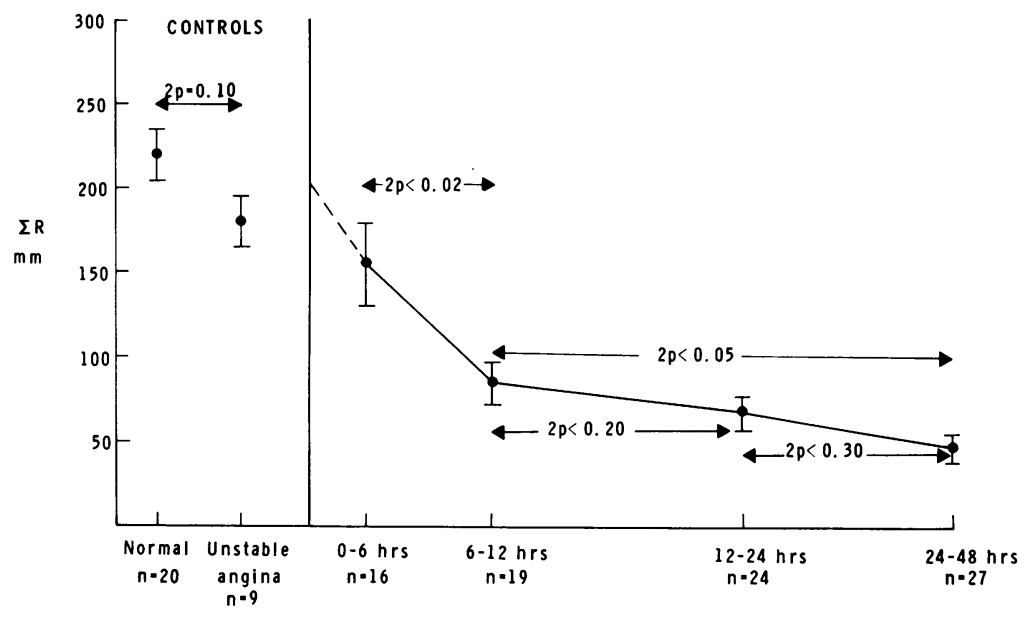

Fig. 1 The $R$ wave loss over 35 praecordial leads in patients with acute anterior infarction. The interrupted line is drawn from the mean of control patients to the first recording.

with no history, clinical evidence, or electrocardiographic abnormalities of ischaemic heart disease ( $\mathrm{n}=10$ ).

(ii) A group of normal healthy male volunteers ( $n=10$ ).

(iii) A group of patients admitted to the coronary care unit with a history suggesting scute myocardial infarction in the previous 12 hours but in whom there was no electrocardiographic or enzyme evidence (from four-hourly $\mathrm{CK} \mathrm{MB}$ ) of proven infarction. None of these patients had a previous history of myocardial infarction $(n=9)$.

The patients were studied to obtain "normal values" for comparison with patients suffering infarction and to confirm the reproducibility of praecordial mapping and the standard 12 lead electrocardiogram. Recordings were examined for beat-to-beat variations during sinus rhythm and atrial fibrillation, variations during quiet and deep breathing, variations caused by electrode repositioning, and those resulting from changes in patient position.

The beat-to-beat variation of measurements of the QRS complex and of ST segment elevation in the same recording during sinus rhythm was small (mean $2.2 \%$ ) compared with a mean of 15 per cent and 20 per cent in two patients who were in atrial fibrillation. The variations resulting from changes in posture and during deep breathing were considerable (mean $12.2 \%$ and $18.5 \%$, respectively). In contrast, the variation caused by electrode repositioning day-to-day variation, and variation during quiet breathing with the patient at 45 degrees and in sinus rhythm, was less than 5.3 per cent. All patients were in sinus rhythm except two who were in atrial fibrillation in whom 10 consecutive beats were averaged.

\section{STATISTICAL METHODS}

Standard paired and unpaired $t$ tests have been used and all $p$ values are 2-tailed.

\section{Results}

(i) CONTROL SUBJECTS

There was no significant difference in $\Sigma \mathrm{R}, \Sigma \mathrm{Q}$, $\Sigma S T+$, or $\Sigma \mathrm{R} / \Sigma(\mathrm{Q}+\mathrm{S})$ between the first two control groups (that is patients without cardiac disease and normal volunteers). They were therefore combined as a normal group. The $\Sigma \mathrm{R}$ was

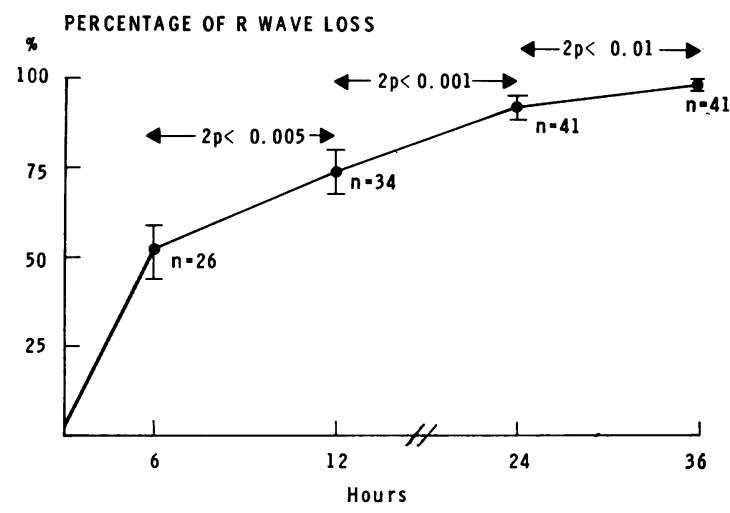

Fig. 2 The percentage loss of $R$ waves in patients with both anterior and inferior infarction. 
Fig. $3 Q$ wave development from 35 praecordial leads in patients with acute anterior infarction. The initial part of the line is drawn from the mean of control to the mean value at the first recording.
Q WAVE DEVELOPMENT IN PATIENTS WITH ANTERIOR MYOCARDIAL INFARCTION

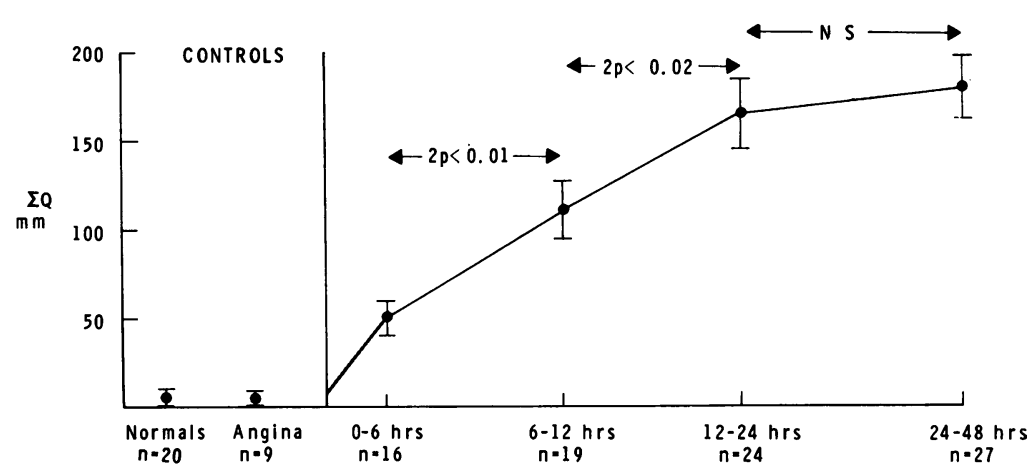

$217 \pm 14 \mathrm{~mm} ; \Sigma \mathrm{Q}$ was $5.05 \pm 1 \cdot 6 ; \Sigma \mathrm{R} / \Sigma \mathrm{Q}+\mathrm{S}$ was $1.72 \pm 0.21 \mathrm{~mm}$; and $\Sigma S T$ + was $12 \pm 2.3 \mathrm{~mm}$ in this group (mean \pm SEM).

Patients admitted to the coronary care unit and diagnosed as having unstable angina had similar $\Sigma Q$ and $\Sigma S T+$ values $(2 \cdot 11 \pm 1 \cdot 4 \mathrm{~mm}$ and $10 \pm 2 \cdot 5$ $\mathrm{mm}$, respectively) compared with the normal group. The $\Sigma R$ and $\Sigma R / Q+S$ were slightly lower than in the normal group (178 $\pm 14 \mathrm{~mm}$ and $1 \cdot 15 \pm 0 \cdot 11$; $2 \mathrm{p}=0 \cdot 10$ ).

\section{(ii) LOSS OF $\mathrm{R}$ WAVES}

Fig. 1 shows the decrease of $\Sigma \mathrm{R}$ waves in patients with anterior infarction. The $\Sigma R$ was significantly lower at recordings obtained less than six hours in these patients compared with the normal controls. $\Sigma R$ decreased from $154 \pm 25$ at recordings obtained within six hours; to $86.08 \pm 12.8 \mathrm{~mm}$ at six to 12 hours; the decrease in $\mathbf{R}$ waves continuing thereafter at a slower rate to $69 \cdot 73 \pm 13.2 \mathrm{~mm}$ at 12 to 24 hours and $48 \cdot 19 \pm 7 \cdot 1 \mathrm{~mm}$ at 24 to 48 hours after the onset of chest pain. No further change in $R$ wave was observed except in the four patients who reinfarcted.

Fig. 2 shows the percentage loss of $R$ waves in the entire group of patients studied. This was calculated from the proportion of $\mathbf{R}$ wave lost at a particular time of recording expressed as a percentage of total decrease in $R$ waves, that is,

\section{Mean "control" $\Sigma \mathrm{R}$ wave $-\Sigma \mathrm{R}$ wave at a}

Mean "control" $\Sigma R$ wave-final $\Sigma R$ wave particular recording $\%$

Fifty-two per cent of the final $R$ wave loss occurred at six hours, 74 per cent at 12 hours, 95 per cent at 24 hours, and 99 per cent at 36 hours after chest pain.

(iii) Q WAVE DEVELOPMENT

Fig 3 shows the $\Sigma Q$ wave development in patients with anterior infarction. At six hours the $\Sigma Q$ is already greater than in control patients. $\Sigma Q$ increased from $52 \cdot 4 \pm 9 \cdot 75 \mathrm{~mm}$ at six hours to 112.20 $\pm 15.5 \mathrm{~mm}$ at six to 12 hours; to $165 \pm 19.4 \mathrm{~mm}$ at 12 to 24 hours; and to $180 \cdot 6 \pm 18 \cdot 8 \mathrm{~mm}$ at 24 to 48 hours after chest pain. Again no further $\Sigma Q$ wave development occurred in any patient except in the four patients who reinfarcted.

Fig. 4 shows the percentage development of $Q$ waves in the total group of patients studied, and it parallels the changes in the $R$ waves. The proportion of final $Q$ waves developed was 42 per cent at six hours; 72 per cent at 12 hours; 93 per cent at 24 hours; and 98 per cent at 36 hours.

\section{(iv) ST SEGMENT CHANGES}

ST segment elevation was maximal at six hours in the whole group and decreased significantly at 12

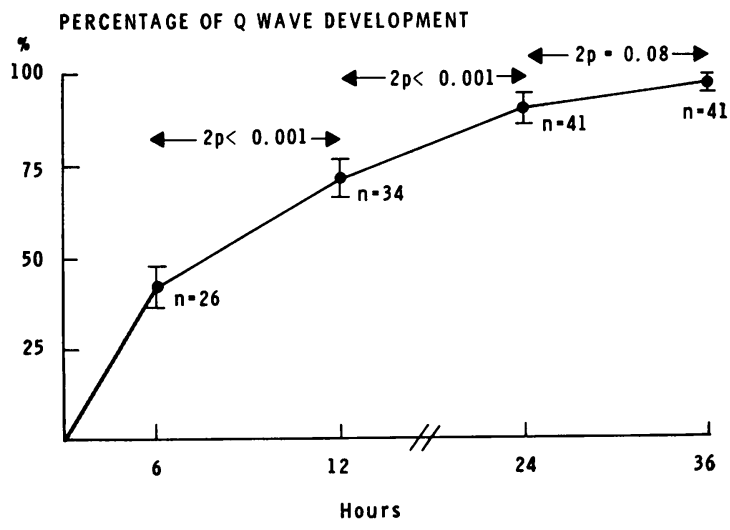

Fig. 4 The percentage of final $Q$ wave developed at a particular time in patients with both anterior and inferior infarction. 
hours. No further change was observed in the first 24 hours.

Fig. 5 shows ST segment changes in the patients with anterior infarction. ST decreases from $80.13 \pm 11.5 \mathrm{~mm}$ at recordings obtained under six hours; to $51 \pm 6.3$ at six to 12 hours; little change occurred in the group after this.

\section{PATTERNS OF INFARCT EVOLUTION}

Considerable variation in the rate of infarction was noted between individual patients, with some patients showing complete $R$ wave loss and $Q$ wave development in as short a time as four hours and some taking as long as 48 hours. To present this variation best, all patients can be broadly divided into three categories based on their electrocardiographic abnormalities.

\section{(1) Type $A$ or rapid infarction $(\mathrm{n}=17)$}

All patients completing electrocardiographic evolution within 12 hours of chest pain have been arbitrarily included in this group. Fig. $6 a$ and $b$ shows these changes in an individual patient and it can be observed that $R$ wave loss and $Q$ wave development were rapid. In addition, the degree of ST elevation at the initial recording was high and decreased rapidly when $R$ loss and $Q$ development were complete. These patients also showed quicker release of CK MB (Fig. 6c and Fig. 9) (mean of $19 \cdot 30 \pm 0.85$ hours after chest pain) compared with the next group (group B).

(2) Type $B$ or slow infarction $(\mathrm{n}=24)$

Included in this group are all patients in whom electrocardiographic evolution of $Q$ waves and $R$ waves continued for longer than 12 hours. Fig. 7a and $b$ shows these changes in an individual patient; it is clear that $\mathbf{R}$ wave loss and $\mathbf{Q}$ development are definitely slower than the patient shown in Fig. 6 . The degree of ST elevation is smaller and persists for longer than in the previous group of patients. Few patients in this group increased their ST segment elevation but in all instances this decreased after complete $R$ wave loss and $Q$ wave development. The duration of $\mathrm{CK} M B$ release in this group was longer than in the earlier group (Fig. 7c and Fig. 9) (mean of $29.9 \pm 2.41$ hours after pain; $2 \mathrm{p}<0.001)$.

\section{(3) Type $C$ or reinfarction}

Four patients from the above groups developed a new episode of typical chest pain and showed further ST elevation, $R$ loss, and $Q$ development accompanied by further release of CK MB (Fig. 8).

\section{RELATION OF INFARCT SIZE TO} DURATION OF ENZYME RELEASE

No significant relation was observed when the total enzyme release was compared with the duration of enzyme release as linear variables. A trend, however, towards smaller infarcts in patients with slower electrocardiographic evolution was observed $(2 \mathrm{p}=0.07)$ (Fig. 9).

\section{Discussion}

The main observation of this study is that infarct evolution is variable in man. In some patients it was complete in as short a time as four hours, whereas in others it took as long as 48 hours. Little previous work has been done on the time course of $Q$ wave or $\mathrm{R}$ wave development in man. Selwyn et al. ${ }^{11} 12$ and Zmyslinski et al. ${ }^{13}$ have both reported a rapid loss of $R$ waves and the development of $Q$ waves, $\mathbf{R}$ wave evolution being completed in six hours in their studies. In our study we have observed such

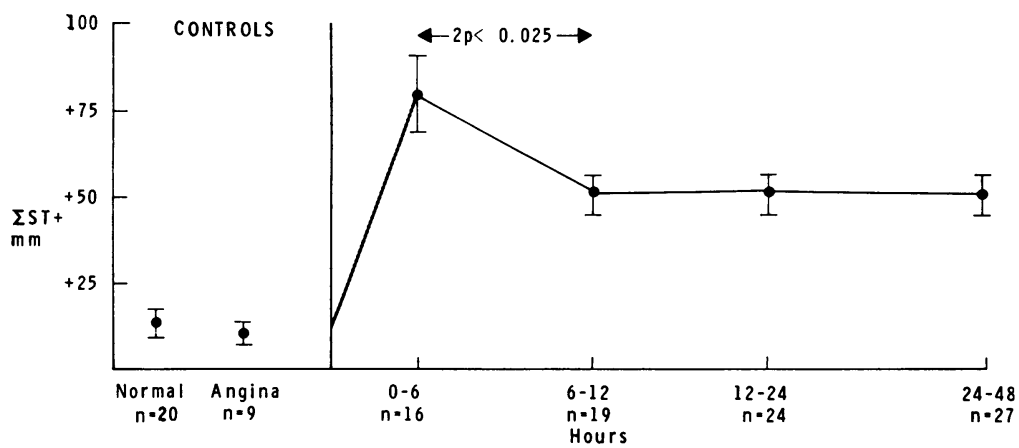

Fig. 5 ST segment elevation from 35 praecordial leads in patients with anterior infarction. The initial part of the line is drawn from the mean of the controls to the mean value at the first recording. 
rapid development of infarct size in less than half the patients, and at 12 hours only 41 per cent of patients studied had completed evolution of the infarct. In 59 per cent of patients, $Q$ wave and $R$

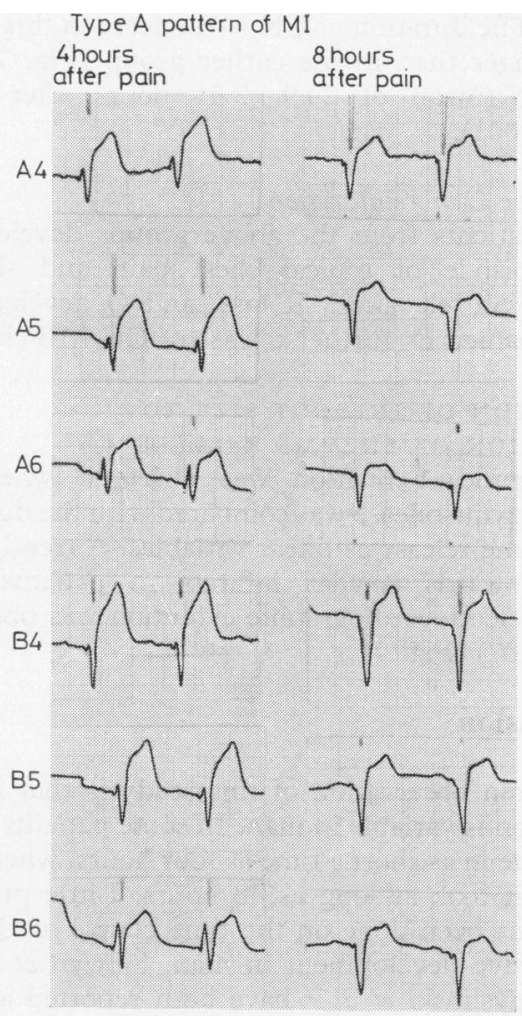

(a)

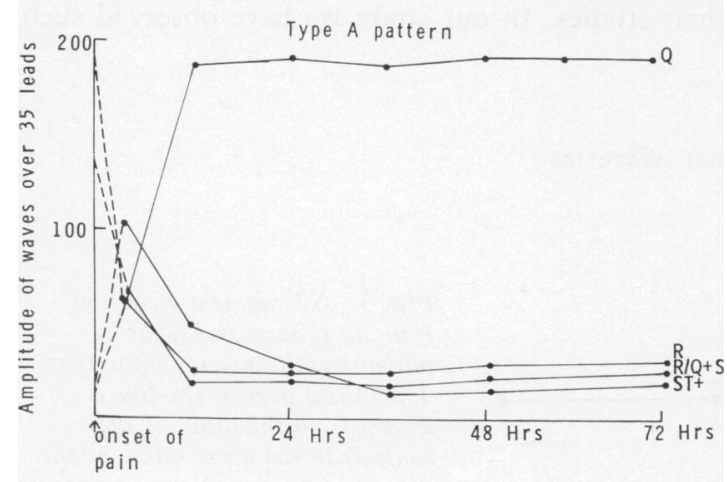

(b)

Fig. 6 (a) Electrocardiograms and (b) schematic presentation of the rapid $R$ loss, $Q$ development, and $S T$ segment changes in a patient with type A infarction. (c) The enzyme release in the above patient.

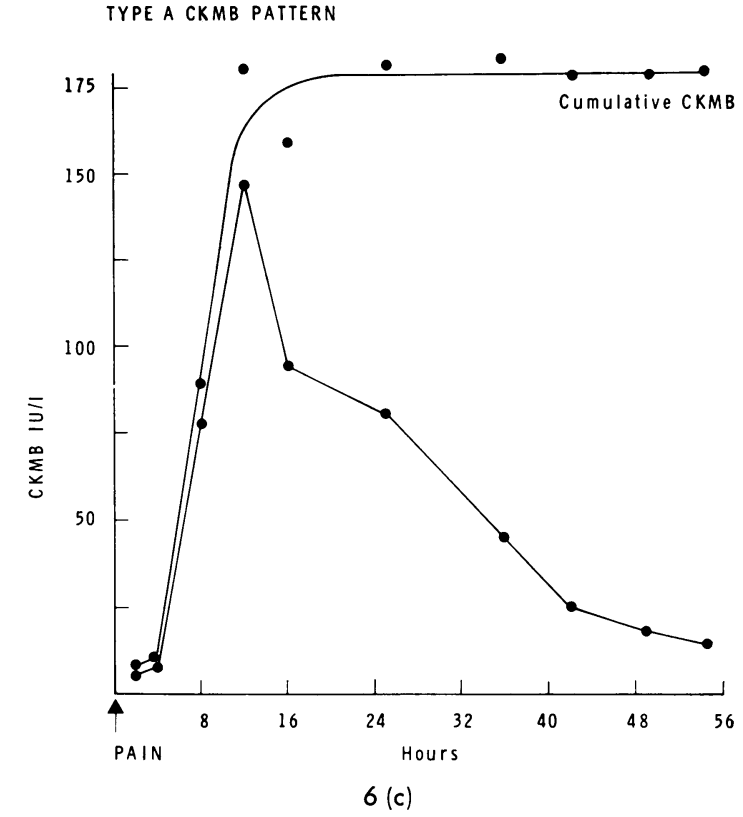

wave evolution continued for longer. In addition, patients with slower electrocardiographic evolution also showed longer duration of enzyme release. This suggests that myocardial necrosis proceeds at a slower rate in these patients.

When the group as a whole is considered, 74 per cent of $R$ wave loss and 68 per cent of $Q$ wave development were complete at 12 hours after the onset of chest pain. The rate of electrocardiographic evolution continued less rapidly after this and was complete on average by 24 hours. The reasons for the longer duration of electrocardiographic abnormalities seen in the type B patients compared with type A must be considered. Whether the patients with the slower electrocardiographic evolution have a slowly extending infarct, or multiple infarcts occurring in rapid succession is uncertain. None of these patients (except those who reinfarcted) had repeated episodes of chest pain. No further reelevation of the ST segment or a separate peak of CK MB release was seen. Cobb et al., ${ }^{14}$ however, have shown in experimental models that very early reinfarction may not produce a separate enzyme peak and may only be manifest by a higher enzyme level and longer duration of enzyme release.

Our data are consistent with the studies of Askenazi et al..$^{15}$ and Henning et al. ${ }^{16}$ which, though not designed to examine the time course of electrocardiographic evolution, provided data suggesting that in many patients $R$ wave loss and $Q$ wave 
changes proceeded for longer than 12 hours and were only complete by 24 hours. In addition, Inoue et al. ${ }^{17}$ have shown that in patients with inferior infarction $Q$ wave changes occurring in leads II, III, and aVF continued for as long as three days even in the absence of reinfarction. These

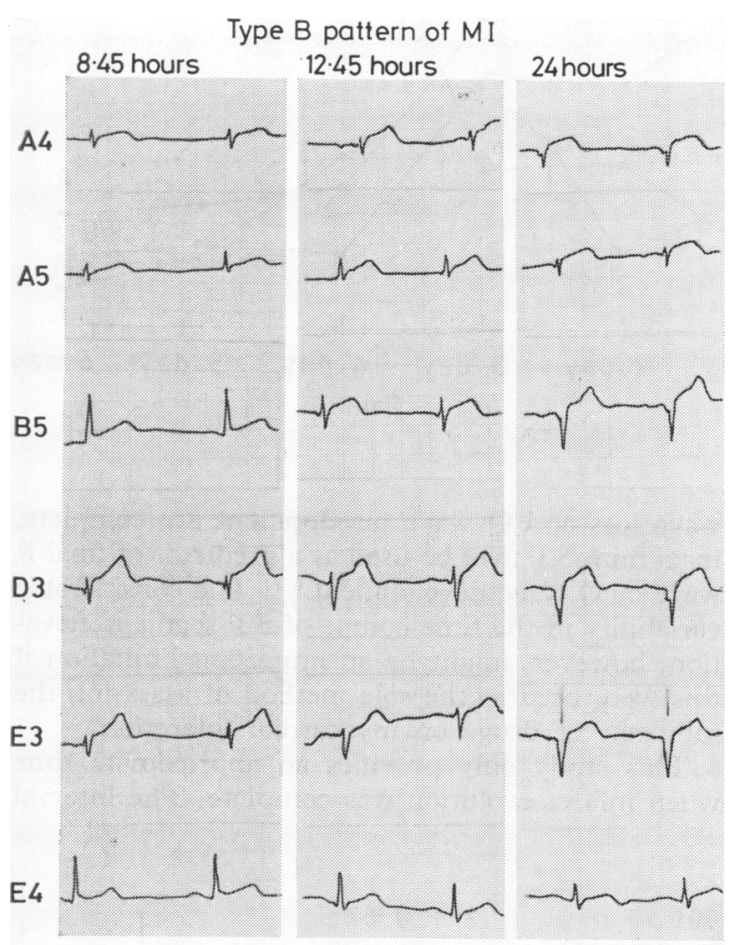

(a)

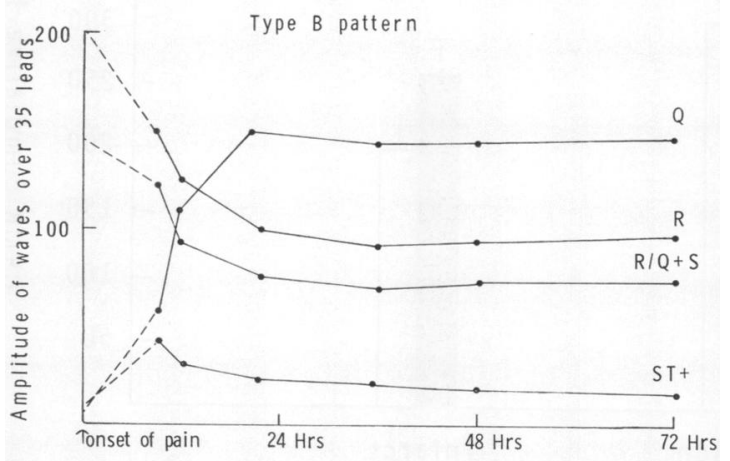

(b)

Fig. 7 (a) Electrocardiograms and (b) schematic presentation of gradual $R$ loss, $Q$ development, and $S T$ segment changes in a patient with type $B$ infarction. (c) The enzyme release in this patient.
TYPE B CKMB PATTERN

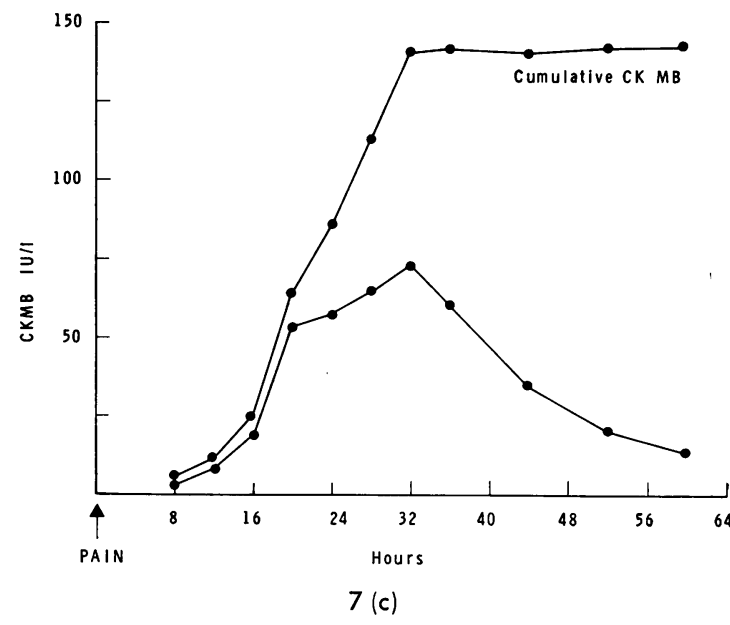

authors also showed a good correlation between the duration of $\mathbf{Q}$ wave development and the duration of enzyme release. Bleifeld and co-workers ${ }^{18}$ have shown three different patterns of creatine kinase release which correspond to the three patterns of electrocardiographic and enzyme release seen in our study. Further, we have observed the same variation and different patterns of infarct evolution in this group of patients using serum myoglobin (unpublished data).

Comparison of the cumulative enzyme release and the duration of enzyme release did not show a significant correlation. A weak trend $(2 p=0.07)$, however, towards larger infarcts in patients with rapid infarction was observed.

Some controversy exists regarding the time course of ST segment elevation. Maroko et al.,19 Madias and Wood, ${ }^{20}$ and Flaherty et al. ${ }^{21}$ have reported that ST segment elevation is stable and changes little in the first 24 hours. In contrast, Selwyn et al., ${ }^{22}$ Zmyslinski et al. ${ }^{13}$ and Essen et al. ${ }^{23}$ have shown that ST elevation is maximum in the first few hours and then rapidly declines considerably by six to 12 hours. Our study provides data to support both viewpoints. Though as a whole the group showed a significant decrease in ST segment elevation from six hours to 12 hours, several patients, especially those showing gradual infarction $(\mathrm{n}=24)$, showed relatively stable ST elevation for 24 hours. Importantly, however, the ST segment remained raised while $Q$ wave and $R$ wave evolution were continuing and always decreased significantly after these were complete. In all four patients with reinfarction, ST segment elevation preceded further $Q$ 
Fig. 8 Schematic representation of the electrocardiographic abnormalities in a patient with type $C$ infarction.

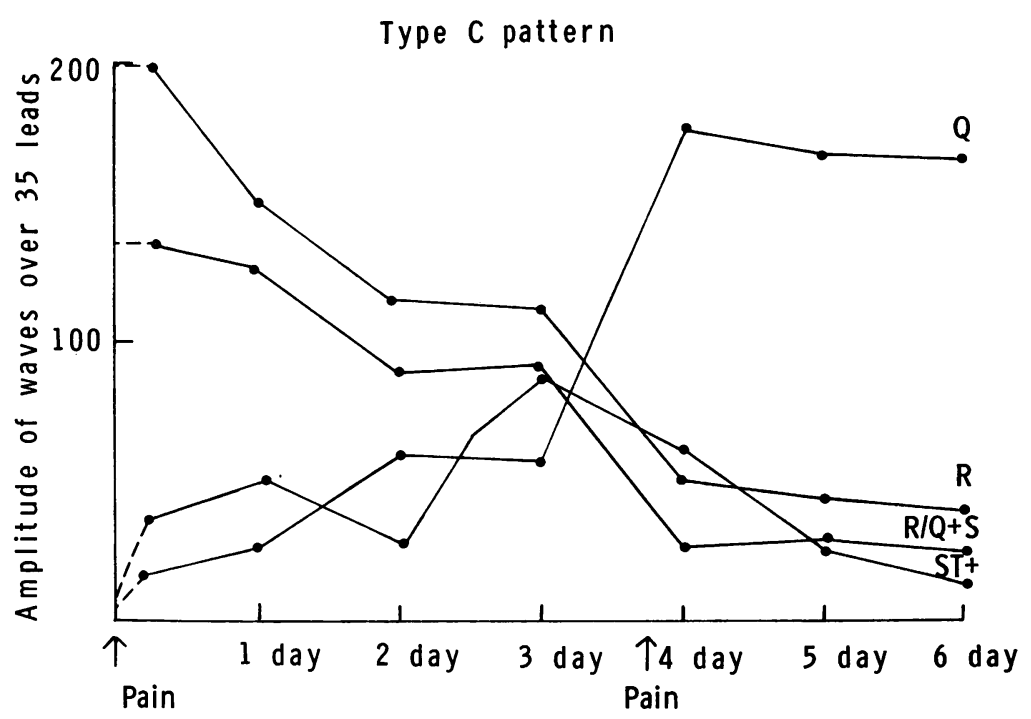

wave development and $\mathbf{R}$ wave loss or re-elevation of CK MB. In two other patients who developed pericarditis, ST re-elevation was not accompanied by further $R$ wave or $Q$ wave changes. In addition to the temporal relation between ST segment and $R$ wave and $Q$ wave changes, we have reported earlier that maximum $\Sigma S T$ elevation correlates well with final $\Sigma Q$ wave or $\Sigma R$ wave amplitude. As $S T$ elevation usually reaches a maximum well before $\mathbf{R}$ wave loss and $\mathrm{Q}$ wave development are complete, maximum ST may be used as a predictor of final $R$ wave or $\mathrm{Q}$ wave development. ${ }^{611}$ The considerable variability in the time course of ST segment elevation, however, might be an important limitation if this were used as the sole method of assessing the influence of drugs on myocardial infarction.

This study only provides an approximate time when infarct evolution was complete. The interval
Fig. 9 On the left, the duration of enzyme release and on the right, infarct size in type $A$ and type $B$ patients.

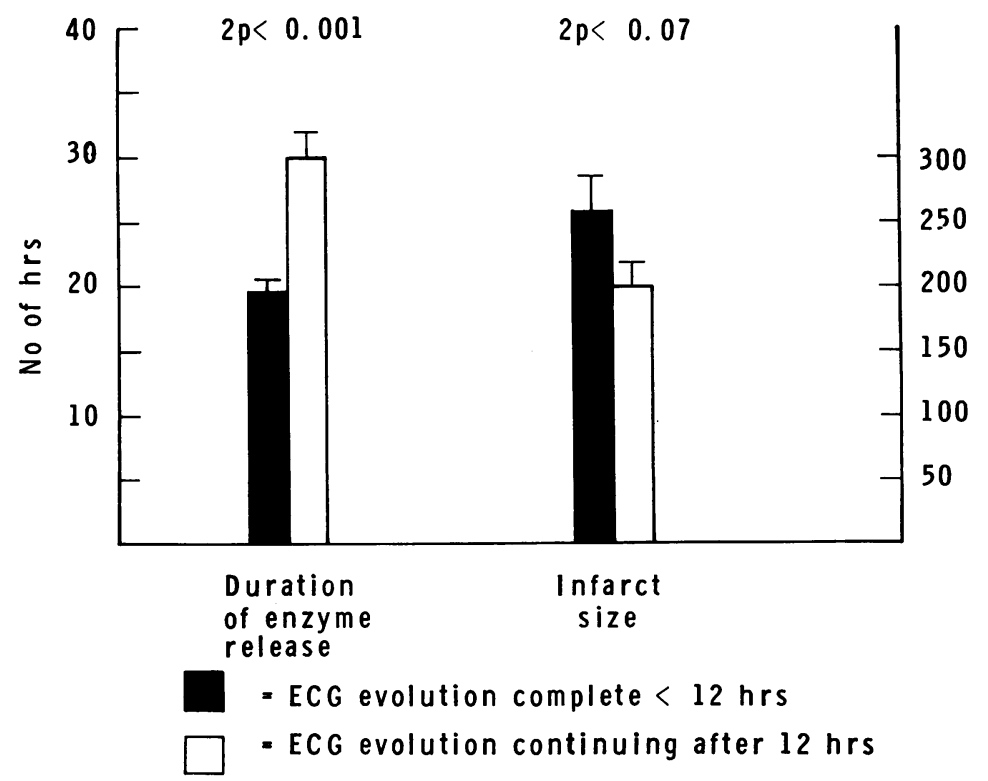


between recordings or blood sampling in individual patients may have led to some overestimation of both the electrocardiographic and enzyme time estimates of infarct evolution. Further, the relation between the time course of cell necrosis and evolving electrocardiographic and enzyme changes is not known. Though maximum $Q$ waves and minimal $R$ waves have been shown to be related to total enzyme release, used as an index of infarct size, ${ }^{6}$ whether evolving $Q$ waves and $R$ waves bear the same quantitative relation to the amount of infarct developed at a particular time is not known. The information obtained, however, has practical relevance as the changes in $R$ waves, $Q$ waves, and ST segment are being used to evaluate the efficacy of interventions designed to limit infarct size in man. ${ }^{24}$ In this study, the onset of chest pain was taken to indicate the onset of infarction; but this may not be a valid assumption. In many instances, accurate timing may not be possible either because of repeated episodes of pain, because of atypical symptoms, or because of prolonged pain. In such instances, onset of pain was taken to be the time of the episode of pain which led to the patient calling his doctor or the ambulance. The degree to which drugs (that is beta-blockers or lignocaine) influenced our results is uncertain. No consistent electrocardiographic pattern was seen with any particular drug. To assess the effect of any drug, however, randomised prospective studies are required. We retained all patients who needed these drugs for though they may have had a complication of infarction, i.e. an arrhythmia, their exclusion might have created bias in patient selection.

Although doubts have been expressed about the reliability of the electrocardiogram ${ }^{25}$ and cumulative enzyme release as direct quantitative estimates of infarct size ${ }^{26}$ most workers accept their validity as indirect but useful indicators of the severity of infarction 8101824 and we have previously shown good quantitative correlations between the electrocardiographic and enzyme methods. ${ }^{6}$ It seems unlikely that the variability in the time course of infarction (observed in our study) is an artefact caused largely by changes in enzyme kinetics or spurious changes in the electrocardiogram, without reflecting actual myocardial necrosis, as we have shown parallel changes in both the electrocardiogram and enzyme measurements.

In conclusion, infarct evolution in man has a more varied time course than that reported earlier. ${ }^{11} 12$ In our study over 50 per cent of electrocardiographic evolution occurred after admission to hospital and suggest that salvage of ischaemic myocardium might be feasible in such patients.
This study was supported by funds from the British Heart Foundation. We are grateful to the nursing staff of the coronary care unit for their help and co-operation.

\section{References}

1 Maroko PR, Kjekshus JK, Sobel BE, et al. Factors influencing infarct size following experimental coronary artery occlusion. Circulation 1971; 43: 67-82.

2 Miura N, Thomas R, Ganz W, et al. The effect of delay in propranolol administration on reduction of myocardial infarct size after experimental coronary artery occlusion in dogs. Circulation 1979; 59: 1148-57.

3 Hillis LD, Fishbein MC, Braunwald E, Maroko PR. The influence of the time interval between coronary artery occlusion and the administration of hyaluronidase on salvage of ischemic myocardium in dogs. Circ Res 1977; 41: 26-31.

4 Baroldi G. Different types of myocardial necrosis in coronary heart disease: a pathophysiologic review of their functional significance. Am Heart $\mathcal{F}$ 1975; 89: $742-52$.

5 Armstrong A, Duncan B, Oliver MF, et al. Natural history of acute coronary heart attacks. A community study. Br Heart f 1972; 34: 67-80.

6 Yusuf S, Lopez R, Maddison A, et al. Value of electrocardiogram in predicting and estimating infarct size in man. Br Heart f 1979; 42: 286-93.

7 Oliver IT. A spectrophotometric method for the determination of creatine phosphokinase and myokinase. Biochem f 1955; 61 : 116-22.

8 Mercer DW, Varat MA. Detection of cardiacspecific creatine kinase isoenzyme in sera with normal or slightly increased total creatine kinase activity. Clin Chem 21: 1088-92.

9 Sobel BE, Bresnahan GF, Shell WE, Yoder RD. Estimation of infarct size in man and its relation to prognosis. Circulation 1972; 46: 640-8.

10 Norris RM, Whitlock RML, Barratt-Boyes C, Small CW. Clinical measurement of myocardial infarct size: modification of a method for the estimation of total creatine phosphokinase release after myocardial infarction. Circulation 1975; 51 : 614-20.

11 Selwyn AP, Ogunro E, Shillingford JP. Loss of electrically active myocardium during anterior infarction in man. Br Heart $\mathcal{F}$ 1977; 39: 1186-91.

12 Selwyn AP, Fox K, Welman E, Shillingford JP. Natural history and evaluation of $Q$ waves during myocardial infarction. $B r$ Heart $\mathcal{F} 1978 ; 40$ : 383-7.

13 Zmyslinski RW, Akiyama T, Biddle TL, Shah PM. Natural course of the S-T segment and QRS complex in patients with acute anterior myocardial infarction. Am f Cardiol 1979; 43: 29-34.

14 Cobb FR, Irvin RG, Hagerty RC, Roe CC. Effect of extension of infarction on serial CK activity. Circulation 1979; 60: 145-54.

15 Askenazi J, Maroko PR, Lesch M, Braunwald E. Usefulness of ST segment elevations as predictors of 
electrocardiographic signs of necrosis in patients with acute myocardial infarction. Br Heart $\mathcal{F} 1977$; 39: 764-70.

16 Henning H, Hardarson T, Francis G, O'Rourke RA, Ryan W, Ross J Jr. Approach to the estimation of myocardial infarct size by analysis of praecordial S-T segment and $\mathrm{R}$ wave maps. Am $\mathcal{f}$ Cardiol 1978; 41: $1-8$.

17 Inoue M., Hori M., Fukui S, et al. Evaluation of evolution of myocardial infarction by serial determinations of serum creatine kinase activity. $\mathrm{Br}$ Heart $\mathcal{F}$ 1977; 39: 485-92.

18 Bleifeld WH, Hanrath P, Mathey D. Serial CPK determinations for evaluation of size and development of acute myocardial infarction. Circulation 1976; 53, suppl I: 108-111.

19 Maroko PR, Davidson DM, Libby P, Hagan AD, Braunwald E. Effects of hyaluronidase administration on myocardial ischemic injury in acute infarction. Ann Intern Med 82: 516-20.

20 Madias JE, Wood WB Jr. Precordial ST-segment mapping 3. Stability of maps in the early phase of acute myocardial infarction. Am Heart $\mathcal{f}$ 1977; 93: 603-9.

21 Flaherty JT, Reid PR, Kelly DT, Taylor DR, Weisfeldt ML, Pitt B. Intravenous nitroglycerin in acute myocardial infarction. Circulation 1975; 51: 132-9.

22 Selwyn AP, Ogunro EA, Shillingford JP. Natural history and evaluation of ST segment changes and MB CK release in acute myocardial infarction. Br Heart $\mathcal{f}$ 1977; 39: 988-94.

23 Essen R v, Merx W, Effert S. Spontaneous course of ST-segment elevation in acute anterior myocardial infarction. Circulation 1979; 59: 105-112.

24 Muller JE, Maroko PR, Braunwald E. Precordial electrocardiographic mapping. Circulation 1978; 57: 1-18.

25 Holland RP, Arnsdorf MR. Solid angle theory and the electrocardiogram: physiologic and quantitative interpretations. Prog Cardiovasc Dis 1977; 19: 430-57.

26 Roe CR, Cobb FR, Starmer CF. The relationship between enzymatic and histologic estimates of the extent of myocardial infarction in conscious dogs with permanent coronary occlusion. Circulation 1977; 55: 438-49.

Requests for reprints to Dr S Yusuf, Department of Cardiovascular Medicine, John Radcliffe Hospital, Headington, Oxford OX3 9DU. 